natureresearch

Check for updates

\title{
OPEN Publisher Correction: Holistic Monte-Carlo optical modelling of biological imaging
}

\author{
Guillem Carles, Paul Zammit \& Andrew R. Harvey
}

Correction to: Scientific Reports https://doi.org/10.1038/s41598-019-51850-1, published online 01 November 2019

This Article contains an error in the order of the Figures. Figures 4 and 5 were published as Figures 5 and 4 respectively. The correct Figures 4 and 5 appear below as Figures 1 and 2. The Figure legends are correct.
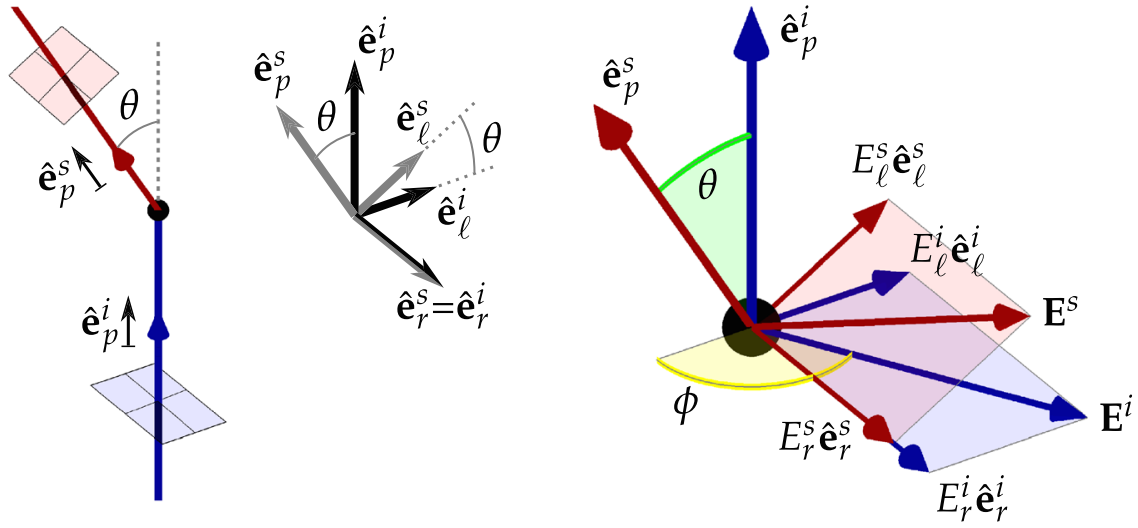

Figure 1. Geometry of a scattering event. Left diagram: incident ray vector $\hat{\mathbf{e}}_{p}^{i}$, and scattered ray vector $\hat{\mathbf{e}}_{p}^{s}$, define the scattering plane common to both vectors and $\theta$ is the scattering angle. Planes for defining polarisation states are represented by the red and blue squares. Centre diagram: the orthonormal co-ordinate systems for $\hat{\mathbf{e}}_{p}^{i}$ and $\hat{\mathbf{e}}_{p}^{s}$; the $r$ direction, common to both systems, is orthogonal to the scattering plane; the propagation direction $p$ and the orthogonal $\ell$ direction for the scattered photon are rotated by $\theta$ in the scattering plane with respect to the incident ray. Right diagram: the electric field $\mathbf{E}^{i}$ of the incident ray (blue) and $\mathbf{E}^{s}$ for the scattered ray (red) are decomposed into the respective $r$ and $\ell$ directions, with respect to the azimuthal angle $\phi$; as for the left diagram, the polarisation planes are shaded red and blue. 


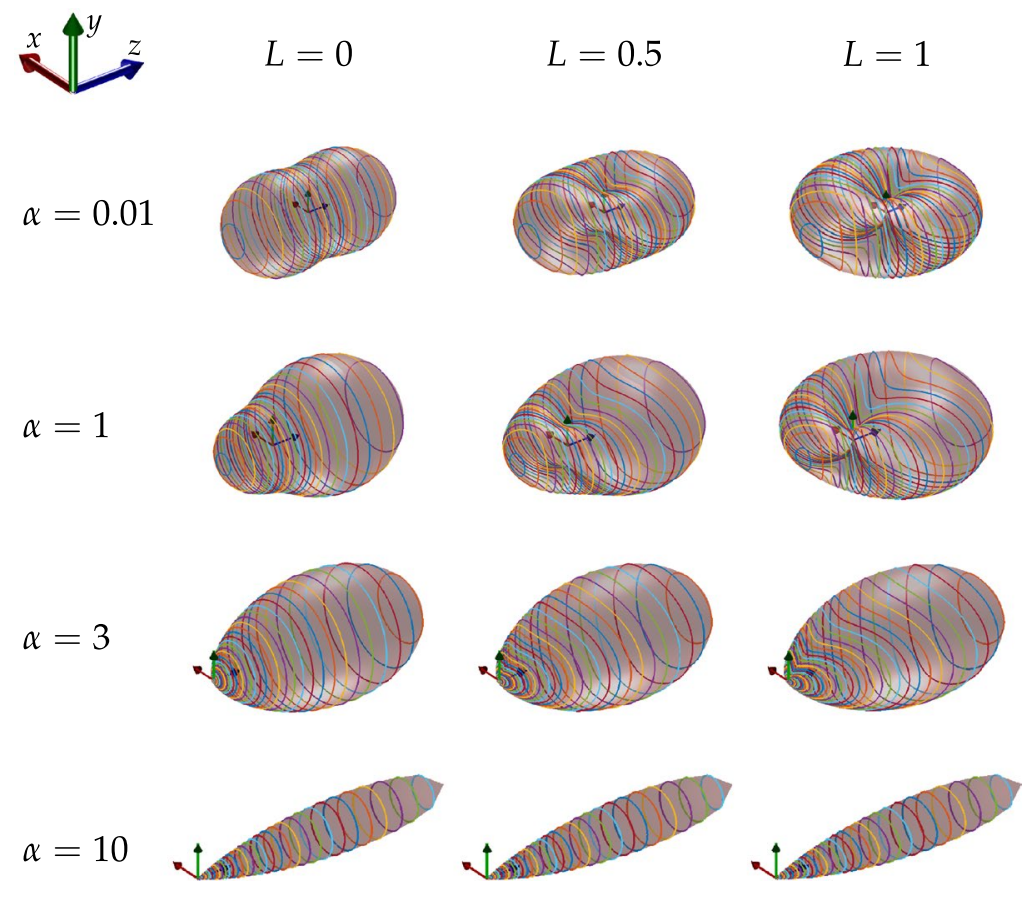

Figure 2. Scattering diagrams. Plots of scattering diagrams depicting the phase functions for Mie scattering, for various particle size parameters, $\alpha=\pi d n / \lambda$ ( $d$ is the particle size, $n$ the index of refraction of the medium, and $\lambda$ the wavelength of the light) and degrees of linear polarisation. The incident ray propagates along $z$ axis and scatters at the origin of the axes. The polarised component of the partially polarised incident light is oriented with the major axis in the $y$ direction. The surfaces correspond to the phase function and coloured lines are contours of constant $\theta$.

\begin{abstract}
(c) (1) Open Access This article is licensed under a Creative Commons Attribution 4.0 International (c) License, which permits use, sharing, adaptation, distribution and reproduction in any medium or format, as long as you give appropriate credit to the original author(s) and the source, provide a link to the Creative Commons license, and indicate if changes were made. The images or other third party material in this article are included in the article's Creative Commons license, unless indicated otherwise in a credit line to the material. If material is not included in the article's Creative Commons license and your intended use is not permitted by statutory regulation or exceeds the permitted use, you will need to obtain permission directly from the copyright holder. To view a copy of this license, visit http://creativecommons.org/licenses/by/4.0/.
\end{abstract}

(C) The Author(s) 2020 